\title{
Planning the properties of a coated abrasive by quality function deployment
}

\author{
Nelli V. Syreyshchikova ${ }^{1, *}$, and Viktor I. Guzeev ${ }^{1}$ \\ ${ }^{1}$ Department of Automated Mechanical Engineering, South Ural State University, Lenin Prosp. 76, \\ Chelyabinsk 454080, Russia
}

\begin{abstract}
Absract. The article presents the procedure for improving the coated abrasive quality using quality function deployment. It shows the results of the process of planning the properties of a coated abrasive based on the consideration of consumer and legislative requirements and operating conditions to achieve the competitiveness of a coated abrasive.
\end{abstract}

Currently, it is obvious that the competitiveness of any enterprise, regardless of its form of ownership and size, primarily depends on the quality of its products. The modern customer compares a high product quality satisfying consumer expectations with the cost (price) of this product. Quality management is one of the key functions of both corporate and project management and the main means of achieving and maintaining the competitiveness of any enterprise [1].

According to the researchers, about $80 \%$ of all defects detected during the production and use of products are preconditioned by an inadequate quality of the development of the product concept, design or preparation for its production. About $60 \%$ of all failures that occur during the product warranty period have their own cause in the erroneous, hasty and imperfect development [2]. According to the Research Department of General Motors Company (USA), during the development and production of the product, the tenfold cost rule is applied [3-4]. The concept of the universal quality management requires to change the approach to the development of new products, since the task is not simply to maintain a certain, albeit a rather high quality level, but also to achieve customer satisfaction [5].

Among the problems the Russian manufacturer currently faces, one of the main ones is the production of competitive products meeting the global standards.

The problem of competition with the products of Japanese and US companies is becoming more acute for European and Russian companies, and the edge of this competitive struggle is:

- increasing the efficiency of production, in particular, reducing the cost of quality competitive product development;

- orientation of all the production process stages, starting from design, towards customer satisfaction;

\footnotetext{
* Corresponding author: snv.ktn@mail.ru
} 
- increasing business culture and improving management in all the production branches.

In order to meet these requirements, it is necessary to use a new technology for the development, planning and technical preparation for the production of items.

The quality of products in general, and abrasive products in particular, is an objective characteristic of their properties formed in the process of design, manufacture and operation. At the stage of product exploitation, the properties inherent in design and manufacture are manifested. Therefore, the evaluation of the abrasive tool quality should include both an evaluation of the tool's operational capability and an evaluation of its performance at manufacturing, i.e. be characterized by the operational and technological indicators.

Out of all the variety of abrasive products, a coated abrasive (CA) comprises 39\%, and grinding operations are used in various industries. Most CAs $(95 \%)$ are made of a grit paper, including the overwhelming majority $(63 \%)$ of products made of a fabric grit paper [6-7].

Quality should be incorporated in the product at the R\&D stage and ensured in the production process. It cannot be obtained by control. When exercising control, the quality level laid down in the product by the developer is certified. Quality can be defined as meeting the customer requirements and ensuring the highest product value. Customer satisfaction is the key to success [8].

An analysis of the state of the CA quality problem shows that the CA production provides for the creation of the CA quality planning process and, accordingly, involves the planning and design stages of a required CA quality level, the stages of determining the achieved quality level. For these purposes, it is advisable to apply system approaches that have become widespread in the international practice and widely used in quality management. There are special technologies for the development and analysis of designed products and processes, such as:

- quality function deployment (QFD) technology,

- function value analysis (FVA),

- failure modes and effects analysis (FMEA),

- function physical analysis (FPhA), etc. [9-10].

The studies of such approaches to quality planning and ways to achieve product quality are covered by the works of both domestic researchers such as: Yu.P. Adler, I.V. Manyagina, I.A. Larioshina, A.V. Aleshkov, M.A. Razno, M.A. Aleshkov, T.A. Babakova, I.N. Selezneva, D.B. Zolotiev, L. Sulivan, E.V. Primak, A.M. Mukhametshina, T.N. Shigabiev, etc., and foreign, such as: J. McElroy, L. Ileigh, M.N. Kennedy, J. Liker, J. Morgan, S.F. Lee, Sai He Ko, Y. Akao, R.G. Day, I.R. Hauser, D. Clausing [1, 6-8; 11-22]. Many researchers believe that the drawbacks of these technologies are mainly connected with the use of expert quality assessment methods. However, they have been successfully used in the design of engineering products. But the use of such technologies for abrasive products, including CAs, is extremely rare.

As a result of analyzing the existing methods for creating the CA quality planning process, it was decided to use a new technology for the development, planning and technical preparation for the production of items. This technology was developed in Japan since the late 60 's and is now increasingly used worldwide in different countries. One of the main tools of this technology is the QFD (Quality Function Deployment) method proposed by E. Akao and S. Mizuno (Japan) in 1966.

The Quality Function Deployment (QFD) methodology [4] is used to include the expressed and implied, existing and potential customer needs in the process of improving the enterprise's products. 
We studied and used the Quality Function Deployment method for planning the CA quality. The basis of the method, which is conventionally called "house of quality", is quality function deployment (QFD) [29]. The essence of the QFD method is a sequence of actions taken by the researcher, producer, manufacturer, etc. for "translating" the consumer requirements to products into the language of technical conditions and standards expressed in quality indicators.

The samples with comparable consumer properties were represented by the CA samples of domestic and foreign manufacturers. We assessed the CA quality level, including grit paper tools of the selected representatives.

The following samples were chosen as a research object: samples No. 1 and No. 5 - grit paper for the CA on the C and K binder according to GOST 27181-86, sample No. 2 - grit paper on the phenol-formaldehyde liquid gum binder according to GOST 13344-79, sample No. 3 - grit paper on the M binder according to GOST 5009-86, sample No. 4 - grit paper on a synthetic binder manufactured by Sait Italian company. A tool made of the Russian grit paper No. 3 is taken as a base sample, in respect of which a quality plan was developed.

To determine the consumer requirements to CAs, we sent 483 requests to consumer enterprises, 248 - to individual enterprises, 200 - to administrations, bases, shops receiving CAs; 35 - to design and engineering offices, leading institutes and laboratories, ministries of the key industries. 176 eligible answers were received. The consumer requirements to CAs we identified. The consumer properties were transformed into CA quality indicators: operational and technological. The grouping of consumer requirements and quality indicators is shown in Fig. 1. It should be noted that most of the CA quality indicators are very close in nature to its consumer properties. In addition to the CA quality indicators chosen according to the applicable standards for grit papers, the proposed and developed quality indicators reflecting the physical and mechanical properties inherent in grit papers and reflecting the consumer requirements were taken for evaluation.

Fig. 1 presents a "house of quality" for a grit paper reflecting the consumer requirements and quality indicators. The expert method was used to evaluate:

- rating of the importance of consumer requirements (1 - minimum, 2 - small, 3 desirable, 4 - necessary, 5 - mandatory);

- mutual relationship between the consumer needs and the tool's indicators (- strong -6 , $\mathrm{o}$ - medium - 3, $\Delta$ - weak - 1).

The roof of the "house of quality" shows the correlation between the parameters of the grit paper quality: - strong positive, o - positive, $\mathrm{x}$ - negative, $\mathrm{xx}$ - strong negative. To evaluate these relationships, we used the correlation analysis data with the reliability of 0.95 , the significance level of the correlation coefficients is 0.59 [7]. Since the consumer properties and the quality indicators are close to each other, the evaluation of the correlation in the main part of the "house and its roof" has approximately the same values.

The right part of the "house of quality" illustrates a comparison of ratings of the consumer properties of grit papers made by various manufacturers (samples No. 1, 2, 4, 5). The degree of satisfaction with consumer properties was determined: 1 - weak, 2 satisfactory. 3 - medium, 4 - good, 5 - excellent. The rating was determined based on a comparison of relative quality indicators. Besides, the right part of the "house of quality" indicates the revealed drawbacks of the competitors' products.

The lower part of the "house of quality" evaluates the importance for each quality indicator (using the calculation method) and a comparison of the values of the quality indicators of all the considered samples (using the expert method) through the rating scale: 1 - poor, 2 - satisfactory, 3 - medium, 4 - good, 5 - excellent. 


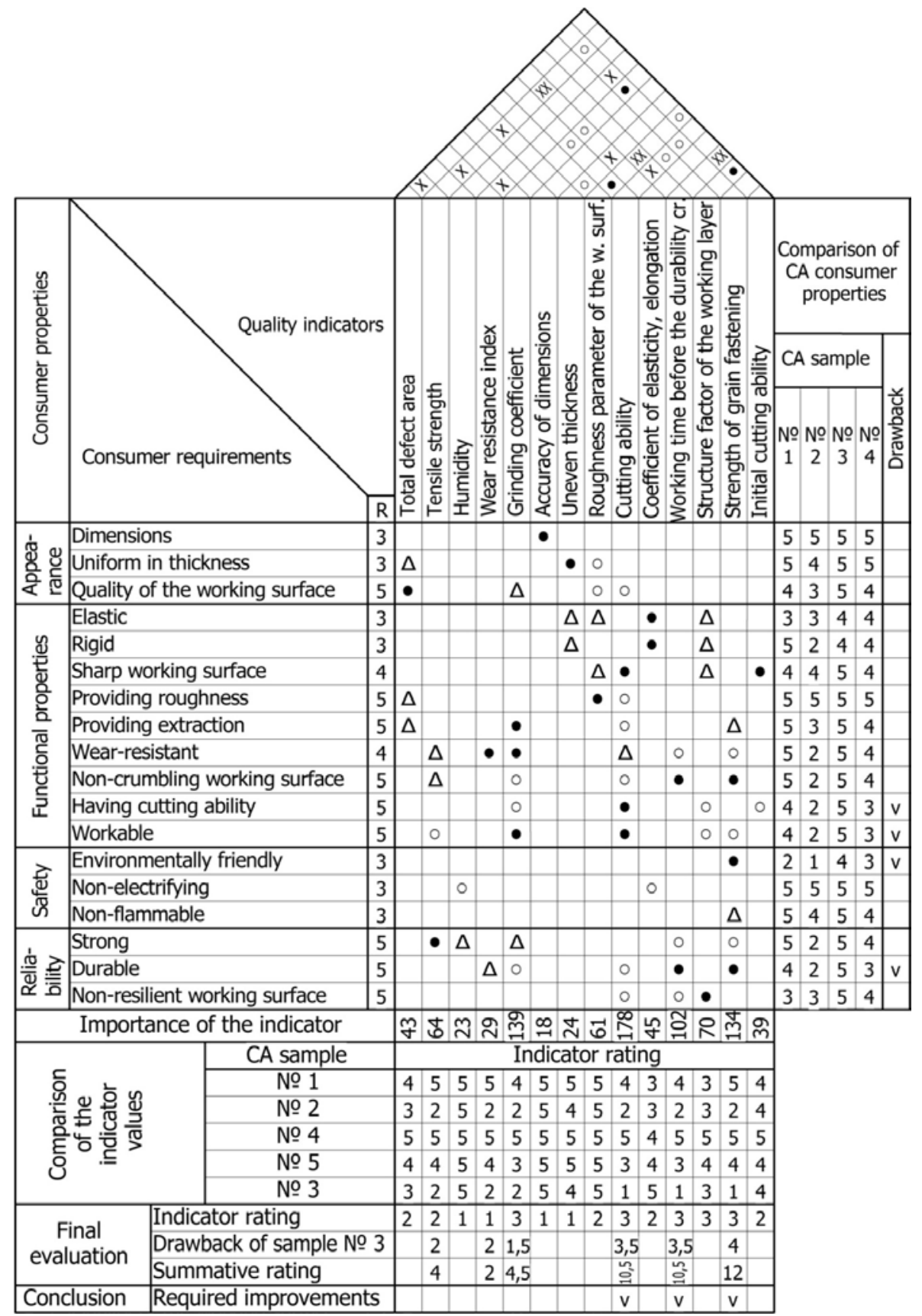

Fig. 1. House of quality of a coated abrasive.

The final evaluation determines the rating of the importance of the tool quality indicator: the highest - 3, the lowest - 1, the average - 2. Thus, the indicators: cutting ability, resistance, grinding coefficient and the indicators: the strength of fastening the grain with the binder received the highest rating - 3; and the indicators: thickness unevenness, dimensional accuracy, humidity and wear resistance index - received the lowest rating 1. 
The lack of competitiveness of sample No. 3 was estimated by the ratio of the average rating of the quality indicators of samples No. 1,2,4,5 to the rating of the indicators of sample No. 3. The basis for the "house of quality" was calculated as the general rating for sample No. 3: combining the lacks of competitiveness of sample No. 3 by the tools quality indicator importance rating.

The QFD method resulted in the conclusion that it is necessary to improve the quality of sample No. 3 by the following parameters: cutting ability and durability of the tool, strength of fastening the working layer.

Based on the conclusions made for a grit paper tool (for example: on the $\mathrm{M}$ binder), when developing a quality plan aimed at obtaining competitive products, it is necessary to manage the technological indicator of the strength of the grain fastening with the binder to create products with the set properties, which will allow us to achieve the required performance: cutting ability, durability, etc.

A quality plan has been developed for the grip paper, in which it is determined what needs to be done to obtain competitive products. To solve the problem of how to do this, a quality plan has been developed for the process of manufacturing the grit paper.

The developed modification of the CA quality function deployment method takes into account the results of the qualimetric evaluation of the samples and the correlation analysis of the quality indicators. Thus, the applied technology of CA quality function deployment allows us to translate the consumer requirements into the quality indicators (operational and technological) and to determine ways of increasing the competitiveness of the tool.

\section{References}

1. Yu.P. Adler, Supplier and customer, Quality and market, or How the organization is configured to meet customer requirements, P. 35-90 (2000)

2. M.N. Kennedy, Why is Toyota better?, 464 p., (2006)

3. J. McAlroy, US Automotive Industry, How to make cars (Quality Function Deployment)?, 7, pp. 10-12, (1987)

4. L. Ileigh, US Automotive Industry, The Advantages of Quality Function Deployment, 7, p. 12, (1987)

5. J. Liker, J. Morgan, The TOYOTA Product Development System. Integrating People, Processes and Technology, 440 p., (2007)

6. N.V. Syreyshchikova, D.Yu. Pimenov, Quality assessment of emery cloth-based abrasive tool using elasticity technological parameter, Procedia Eng. 206, 1155-1160 (2017)

7. N.V. Syreyshchikova, A.A. Syreyshchikov, Proceedings of the 5th International Scientific-Technical Conference, Ensuring and improving the quality of machines during the life cycle phases, Planning the properties of a coated abrasive using the quality deployment method, pp. 37-38, (2005)

8. Yu.P. Adler, Quality Management Methods, Quality and market, or How the organization is configured to meet customer requirements, 8, pp. 46-48, (1999)

9. A.M. Kuzmin, Quality Management Methods, The history of the appearance, development and use of the quality function deployment method, 1, (2002)

10. I.V. Manyagina, I.A. Larioshina, Quality Management Methods, 2, pp. 46-48, (2017)

11. A.V. Aleshkov, M.A. Aleshkov, Bailar Rasearch Journal, About the prospects of QFDanalysis when developing innovative products, 6, 1, P. 10, (2015) 
12. M.A. Razno, Quality Management Methods, QFD: analyze the customer requirements, 7, pp. 4-10 (2011)

13. Y. Akao, Productivity Press, Quality Function Deployment Integration Customer Requirements Into Product Design, (1990)

14. T.A. Babakova, I.N. Selezneva, Theses of the report of the XV International Journal. Scientific-Practical Conference of Young Scientists and Students, Application of QFDmethodology for quality management of ion exchangers, 1, 108 p., (2009)

15. T.A. Babakova, D.B. Zotiev, Directory. Engineering Journal, Setting of Fuzzy Parameters of the QFD - Quality Management Methodology, 146, 5, pp. 48-52, (2009)

16. R.G. Day, Quality Press, Quality Function Deployment Linking a Company with its Customers, (1993)

17. J.R. Hauser, D. Clausing, Focus on Quality, House of Quality, 1, P. 85-102, (1992)

18. L. Sullivan, Focus on Quality, Quality Function Deployment, 3-4, pp. 156-177, (1992)

19. Materials of 20th Symposium on QFD, Santa Fe NM USA, October 22-23, (2008)

20. S.F. Lee, Andrew Sai On Ko, Quality Management, Building balanced scorecard with SWOT analysis, and implementing "Sun Tzu's The Art of Business Management Strategies" on QFD methodology, 2, (2008)

21. E.V. Primak, A.M. Mukhametshina, T.N. Shigabiev, Scientific notes of Bauman Kazan State Academy of Veterinary Medicine, Application of the QFD method to improve the quality of bakery products, 208, P. 99-104, (2011)

22. J.R. Hauser, D. Clausing, Harvard Business Review, The House of Quality, 66, 3, Pp. 53-73, (1988) 